\title{
Consumer health information
}

\author{
Compiled by Susan Murray
}

\section{Canadian Health Network (CHN) update (www.canadian-health-network.ca)}

You can order $\mathrm{CHN}$ promotional material online. A variety of attractive material is available, such as magnets, pens, posters, bookmarks, pamphlets, and several information sheets. These items are great for outreach activities and are quality health information resources that you can recommend with confidence. Consider having a supply available for your library users. Here are the directions to access the CHN promotional material:

(1) Go to www.canadian-health-network.ca

(2) Select "Contact Us"

(3) Scroll down the page and locate the heading "Still have questions?"

(4) Choose "Order promotional items"

Furthermore, in the "Still have questions?" section, please note that you or your users can send a question to CHN and receive a customized response within 5 days. Select the disease prevention, group, or topic area, and send your question to the affiliate who is responsible for that area. For example, you could direct a question about complementary and alternative health to the Consumer Health Information Service at the Toronto Public Library. Please note that only health information, not health advice, can be provided.

A special youth area was launched in October 2006, and it can be accessed from the CHN's main Web page. If you have young family members and (or) library users interested in youth health, direct them to this customized interface.

Sign up and encourage your users to register for Healthlink, CHN's bimonthly e-bulletin, to keep informed of the dynamic content available on $\mathrm{CHN}$, including new articles and notable health dates. Click on the "Subscribe To Our Healthlink Newsletter" link at the top right of the CHN's main Web page.

\section{Health literacy}

"Low health literacy is irrefutably linked to unsafe and inefficient care, poor outcomes and increased costs". The US Joint Commission Accreditation of Healthcare Organizations (JCAHO) held a public policy symposium in Chicago, 2627 June 2006, titled "Health literacy: the foundation for patient safety, empowerment, and quality health care". Julie Esparza has an article in the September 2006 MLA News dis- cussing the symposium. She was particularly and rightfully concerned that the symposium, with $12 \mathrm{~h}$ of health literacy programming, lacked the involvement of librarians. She stated that "we need to do more to increase awareness of the significant role that we can (and already do) play in educating individuals with low health literacy levels."

There are substantial health literacy resources available on the Medical Library Association (MLA) site at http:// www.mlanet.org/resources/healthlit/healthlit_resources.html.

I taught a continuing education course at the Canadian Health Libraries Association / Association des bibliothèques de la santé du Canada (CHLA / ABSC) Conference 2006 titled "Plain talk about health literacy". This course is accredited by MLA and CHLA / ABSC and can be presented if your chapter is interested in contacting me (http://www.chla-absc.ca/2006/). I will also be giving a presentation on this topic at the Ontario Library Association's Superconference being held 31 January - 3 February 2007 (no date yet set for the presentation). For more information, see http://www.accessola.com/site/showPage. cgi?page=education/superconference/index.html.

\section{MedlinePlus}

Fourteen illustrated body maps were added to provide an interactive way to navigate MedlinePlus health topics. Each of the "Body Locations/Systems" on the Health Topics home page links to an interactive body map and a listing of related health topics.

\section{MLA to participate in Google Health Co-op}

\section{http://www.google.com/coop/topic?cx=health_devel}

The MLA Consumer and Patient Health Information Section (CAPHIS) is participating in Google Health. CAPHIS volunteers will tag, label, and annotate Web sites to help people find high-quality information faster. Other organizations who have signed on to the project include the National Library of Medicine, Centers for Disease Control and Prevention, Mayo Clinic, New York Online Access to Health, New England Journal of Medicine, Harvard Medical School, and Stanford Hospital and Clinics. 


\section{Consumer health and PubMed}

Tip! Do the following to limit your PubMed search to the consumer health journal subset: enter subject, such as diabetes AND consumerj[sb].

\section{Notable new publications and products}

Canadian Health, a new bimonthly journal for consumers published by the Canadian Medical Association, debuts in October 2006. The publication will be placed in over 25000 physicians offices across Canada, primarily to general practitioners and family medicine clinics that see an average of 50 patients per day. For more information, see http://www.cma.ca/index.cfm?ci_id=10035855\&la_id=1.

Another publication of interest is The Grey House Rare Disorders Directory, 2006/07 (1st ed., Yale University School of Medicine and Yale New Haven Children's Hospital Staff, Grey House Publishing, New Haven, Conn., 2006, US\$165.00, ISBN 1-59237-123-X).

The ProQuest Family Health database covers an extensive range of subjects of value in the public library context, such as sports injuries, women's health, nutrition, midwifery, eye care, and dentistry. It covers more than 355 journals, including the following:

(i) Professional medical journals, such as Lancet and New England Journal of Medicine

(ii) Several Canadian titles, such as Chatelaine and $A$ Friend Indeed

(iii) Consumer and news magazines, such as Men's Health. Exceptional Children, Diabetes, Journal of Health and Social Behavior, Journal of Youth and Adolescence, Women's Health Weekly, Pediatrics for Parents, and Occupational Health

For a complete list of titles, enter the name of the database at http://il.proquest.com/tls/jsp/list/tlsSearch.jsp. For more information, see the information sheet at http:// www.il.proquest.com/cgi-in/format/printer.pl or contact Barbara Waddell, Account Manager (e-mail: bwaddell@ micromedia.ca; telephone: 416-369-2577; toll free: 800-3872689, ext. 2577).

\section{Consumer health information readings}

http://www.haworthpress.com/store/product.asp?sid= H676J9EAJ7WL9MLEN0NDCDFKWFDL5QMB\&sku= J381\&Auth'Type=4

There are some articles in upcoming issues of the Journal of Consumer Health on the Internet that examine non-
Internet topics. Although you have to pay to view an article, a table of contents for the journal is available at the Web page listed above. Select "Complete Contents for Current \& Past Volumes" from the Journal Information column located on the right side of the screen. The following are a few notable articles:

Canadian Adverse Drug Reaction Monitoring Program (CADRMP) - Adverse Reaction (AR) Database <http:// www.hc-sc.gc.ca/dhp-mps/medeff/databasdon/index_e.html>. By Nandita S. Mani. 2006;10(3):93-101.

Outreach to public libraries, senior centers, and clinics to improve patient and consumer health care: an update. By Naomi C. Broering, Stacey L. Gomes, and Gregory A. Chauncey. 2006;10(3):1-19.

EBSCO Health Library. By Joann L Chateau and Fareed Nawaz. 2006;10(4): 83-93.

\section{Consumer Health Information Service (CHIS): updated guides}

Several CHIS guides have been updated (http://www. tpl.toronto.on.ca/uni_chi_index.jsp):

(i) Consumer Health Information - Selected Bibliography of Readings

(ii) Core Collection of Recommended Titles / Consumer Health Books - If You Have \$1900

(iii) Periodicals Currently Held at the Consumer Health Information Service

(iv) List of Periodicals by Subject

Our annotated guides, Healthnavigators, are being updated and moved to a new home on our Web site and may not be available when this issue goes to press. We apologize for any inconvenience. Please contact CHIS directly for print copies of the guides on these topics:

- Attention deficit hyperactivity disorder (ADHD)

- Air pollution - indoor

- Air pollution - outdoor

- Alzheimer disease

- Anaphylaxis

- Arthritis

- Asthma

- Back pain

- Breast cancer

- Complementary and alternative medicine

- Congestive obstructive pulmonary disease (COPD)

- Depression

- Fibromyalgia

- Menopause 